\title{
Expression of the Mitochondrial Uncoupling Protein Gene from the aP2 Gene Promoter Prevents Genetic Obesity
}

\author{
Jan Kopecky, ${ }^{*}$ George Clarke, ${ }^{*}$ Sven Enerbäck, ${ }^{\star 1}$ Bruce Spiegelman, ${ }^{\ddagger}$ and Leslie P. Kozak* \\ *The Jackson Laboratory, Bar Harbor, Maine 04609; and ${ }^{\ddagger}$ Dana Farber Cancer Institute and the Department of Cell Biology, \\ Harvard Medical School, Boston, Massachusetts 02115
}

\begin{abstract}
The brown fat-specific mitochondrial uncoupling protein (UCP) provides a mechanism for generating heat by uncoupling respiration and oxidative phosphorylation. It has been suggested that this system of thermogenesis can provide a defense against obesity. To test this idea, we created a transgenic mouse in which the fat-specific aP2 gene promoter directed $U c p$ expression in white fat and provided for the constitutive expression of $U c p$ in brown fat. Transgenic mice showed both Ucp mRNA and immunoreactive UCP in white fat at $2-10 \%$ the level normally measured in brown fat. A reduction in subcutaneous fat of aP2-Ucp C57BL/6J mice was observed at 3 mo of age. When the transgene was expressed in $A^{v y}$ genetically obese mice reductions in total body weight and subcutaneous fat stores were observed. Female transgenic $A^{\text {vy }}$ mice at 13 mo of age weighed 35 grams, a weight indistinguishable from nontransgenic C57BL/6J mice. Gonadal fat showed an increase in a novel adipocyte derivative that did not accumulate lipids and that constituted $\sim 80 \%$ of the mass of the tissue in $A^{v y}$ transgenic. A major effect of aP2-Ucp in brown fat was to reduce endogenous gene expression by as much as $95 \%$. The results suggest that UCP synthesized from the aP2 gene promoter is thermogenically active and capable of reducing fat stores. (J. Clin. Invest. 1995. 96:2914-2923.) Key words: thermoregulation • transgenic mice • sex dimorphism
\end{abstract}

\section{Introduction}

The capacity for white adipose tissue to store fat is a function of the repertoire of fat-specific genes that provides those enzymes and proteins required for the transport and conversion of energy substrates into fat and others which enable it to be mobilized for the energy needs of the body (1). This function to store energy in its most concentrated form makes the white adipocyte one of the most energetically efficient cells in the body. However, there is another adipocyte, the brown adipocyte, that expresses a similar set of fat-specific genes plus a few

Address correspondence to Leslie P. Kozak, The Jackson Laboratory, Bar Harbor, ME 04609. Phone: 207-288-3371; FAX: 207-288-5172. Jan Kopecky's present address is Institute of Physiology, Czech Academy of Sciences, Vídenská 1083, 14220 Prague 4, Czech Republic. Sven Enerbäck's present address is Department of Molecular Biology, University of Göteborg, Medicinareg 9C, S-413 90 Göteborg, Sweden.

Received for publication 13 March 1995 and accepted in revised form 27 July 1995.

J. Clin. Invest.

(C) The American Society for Clinical Investigation, Inc.

$0021-9738 / 95 / 12 / 2914 / 10 \quad \$ 2.00$

Volume 96, December 1995, 2914-2923 others that enable it to produce heat as its major function. The mechanism of thermogenesis in brown adipocytes is based on the mitochondrial uncoupling protein (UCP), ${ }^{1}$ a proton channel protein in the inner mitochondrial membrane which converts the electrochemical potential of the mitochondria into heat instead of ATP (2). Reflecting this novel physiological uncoupling of oxidative phosphorylation, brown adipose tissue mitochondria are endowed with a high oxidative capacity, a high content of cytochrome oxidase, but a low content of ATP synthetase $(3,4)$ Accordingly, two features distinguish white and brown adipocytes, one qualitative, the expression of $U c p$, and the other quantitative, the high content of mitochondria with their unique stoichiometry of protein complexes in the inner membrane.

The idea that $U c p$ might be involved in regulating energy balance and that abnormalities in brown fat might result in obesity was first proposed by Rothwell and Stock (5). In support of the idea, it was pointed out that genetically obese mice are not able to withstand exposure to cold and therefore have defective brown fat thermogenesis $(6,7)$ The defective thermogenesis would underlie the obesity. In addition to an apparent functional defect in genetically obese mice, activation of thermogenesis in brown fat by diet also suggests a causal link between brown fat metabolism and energy balance (for a review see 8 ). Nevertheless, the complexity due to (1) the relationship of energy balance to the action of the sympathetic nervous system, and (2) the affects of the progression of obesity on the action of the sympathetic nervous system and energy metabolism has precluded our ability to establish a direct causal relationship between obesity and brown fat thermogenesis. Yet the idea that perturbations in a system, the function of which is known to only be heat production, should affect obesity is inherently appealing. The recent demonstration that the ablation of brown fat in mice, caused by a transgene of the $U c p$ promoter driving expression of the diptheria toxin gene, results in reduced brown fat thermogenesis and obesity has provided the first direct evidence for a causal relationship between brown fat thermogenesis and obesity (9) Conversely, the reciprocal experiment to overexpress $U c p$ in white adipocytes would test the idea that enhanced nonshivering thermogenesis can reduce obesity. Thus, we have constructed transgenic mice in which the $U c p$ gene is driven by the fat-specific aP2 promoter to achieve enhanced expression in both brown and white fat (10) These mice show a marked reduction in adiposity and, in some instances, a resistance to obesity.

\section{Methods}

Construction of the aP2-Ucp transgene. The Ucp minigene pBluescript plasmid, lacking exons 3,4 , and 5, was cut at the BglI site at +109 in

1. Abbreviation used in this paper: UCP, uncoupling protein. 
exon 1 to remove the $U c p 5^{\prime}$ flanking region. A NotI linker was added to the BglI site (11), (Fig. 1) and the 4.25-kb fragment extending from the new NotI site to the ClaI site in the polylinker of the $U c p$ minigene plasmid was directionally cloned into the polylinker region of Bluescript SK $+/-$. A 3.7-kb SacI fragment carrying exons 3, 4, and 5 and the intron sequences missing from the Ucp minigene was ligated into a Smal site located between exons 2 and 6 of the minigene to regenerate the intron/exon domain of Ucp. The ClaI site located $17 \mathrm{bp}$ from the $5^{\prime}$ end of the 5.4-kb aP2 5' flanking region was replaced by a NotI linker and then the entire 5.4-kb fragment which also carried the first 21 bp of the aP2 gene transcript was ligated into the NotI site at the $5^{\prime}$ end of the Ucp construct (10). Plasmids with the proper 5' to $3^{\prime}$ orientations were selected. A 13.5-Kb SacII-XhoI fragment carrying the aP2 regulatory region and the $U c p$ gene was isolated by preparative electrophoresis in an agarose gel and purified using a Gene Clean Kit (BIO 101, Inc., Vista, CA). Microinjection into C57BL/6J mouse embryoes was carried out as previously described (12).

Transgenic founders were identified and gene copy number determined by Southern blot analysis of tail DNA cut with BglII and probed with a $1.4 \mathrm{~kb}$ HindIII-KpnI fragment labelled with random primers (13). Subsequently, mice carrying the transgene were identified by PCR carried out with the primer pair Ucp-6 (CAATCTGGGCTTAACGGGTCC) and $U c p-180$ (CTGAAGACAACAGTGGCACTG) for the endogenous $U c p$ gene and aP2-83 (GAAATGATGTGGCCCCCATTG) and $U c p-180$ for the transgene.

RNA analysis. Total RNA was isolated using guanidinium thiocyanate as described (14). Ucp mRNA was analyzed by Northern blot analysis (15); however, in order to distinguish between the endogenous gene transcript and the transgene transcript a primer extension assay was developed. Priming the reverse transcriptase reaction with CCTGAAGACAACAGTGGCACTGTTGCCTGATGCGGGCACGAAGCC yields a 132 base transcript from the aP2-Ucp transgene and a 180 base transcript from the endogenous $U c p$ gene (see Fig. 2). The reaction was performed in the PTC-100 thermocycler (MJ Research, Inc. Watertown, MA) as follows: lyophilize $20 \mu \mathrm{g}$ of total RNA in a PCR tube, add $3 \mu \mathrm{l}$ of $5 \times$ reverse transcriptase buffer (GIBCO), $1 \mu \mathrm{l}$ of $10 \mathrm{mM}$ DTT, $300,000 \mathrm{dpm}$ ATP-P ${ }^{32}$ labeled oligonucleotide primer $\left(10^{6} \mathrm{dpm} / \mathrm{ng}\right)$, and water to $10 \mu \mathrm{l}$, and overlay with oil. Incubate in the thermocycler at $75^{\circ} \mathrm{C}$ for $3 \mathrm{~min}$, slope to $55^{\circ} \mathrm{C}$ at a rate of $1^{\circ}$ per 6 $\mathrm{min}$, and leave at $55^{\circ} \mathrm{C}$ for $15 \mathrm{~min}$. Remove tubes from the thermocycler and add $0.5 \mu \mathrm{l}$ of RNAsin (40 U/ $\mu \mathrm{l}$; Promega), 1.0 $\mu \mathrm{l} \mathrm{M-MLV} \mathrm{reverse}$ transcriptase (200 U/ $\mu$ l; GIBCO BRL, Gaithersberg, MD), $0.75 \mu 110$ $\mathrm{mM}$ dNTPs, $1 \mu \mathrm{l}$ DTT and water to $15 \mu \mathrm{l}$. Continue the incubation in the thermocycler for $1 \mathrm{~h}$ at $42^{\circ} \mathrm{C}$. Transfer the reaction mixture, free of oil, to a new tube, remove a 7.5- $\mu$ l aliquot to a fresh PCR tube, add 4 $\mu \mathrm{l}$ of loading dye buffer ( $80 \%$ formamide, $0.05 \mathrm{M}$ sodium hydroxide, $1 \mathrm{mg} / \mathrm{ml}$ xylene cyanol, $1 \mathrm{mg} / \mathrm{ml}$ bromophenol blue) and incubate in the thermocycler for $6 \mathrm{~min}$ at $90^{\circ} \mathrm{C}$. The products are separated on a $6 \%$ polyacrylamide sequencing gel.

UCP analysis by immunoblots. Quantitation of UCP was accomplished by immunoblots (16). Tissues were homogenized on ice and maintained in the cold in nine volumes of $10 \mathrm{mM}$ Tris- $\mathrm{HCl}, 1 \mathrm{mM}$ EDTA pH 7.5 and centrifuged at $600 \mathrm{~g}$ for $5 \mathrm{~min}$. The supernatant solution, free of the lipid layer, was centrifuged at $100,000 \mathrm{~g}$ for 30 min and the membranous pellet was used for immunoblots with a rabbit anti-hamster UCP antibody and I ${ }^{125}$ goat anti-rabbit IgG (New England Nuclear, Boston, MA). Protein concentrations of the membrane preparations were determined by the bicinchoninic (17). For immunoblot analysis proteins from membrane fractions of brown and white fat $(0.2-$ 0.4 and $5-10 \mu \mathrm{g}$, respectively) were separated by SDS-polyacrylamide electrophoresis. Each blot carried a range of known amounts of UCP, purified as described by Klingenberg (18), in order to construct a standard curve to quantify the test samples. Standards of purified UCP contained $20-150 \mathrm{ng}$ of protein as estimated by the method of Schaffner and Weissman (19) using BSA as a standard. The amount of $I^{125}$ bound to the membrane filter was determined with the Fujix BAS 1000 BioImaging Analyzer.

Histology. Tissues were fixed in Bouin's fixative and embedded in paraffin. Sections were stained with hematoxylin and eosin. In addition,
A
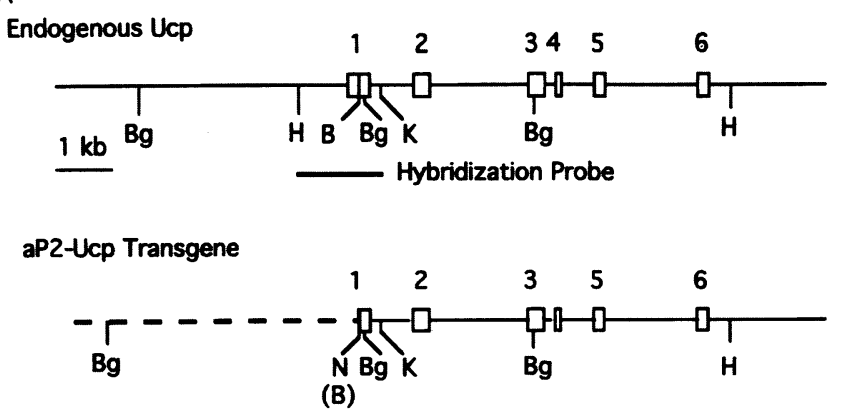

B

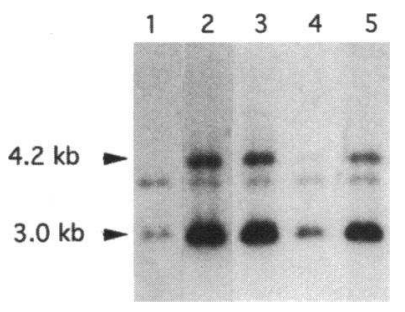

Figure 1. (A) Schematic representation of the normal, endogenous $U c p$ gene and the aP2-Ucp transgene. The aP2 gene promoter (dashed line) was ligated to the $U c p$ gene at a $\mathrm{BglI}$ site in the untranslated region of exon 1. Bg, BglII; H, HindIII; B, BglI; K, KpnI; N, NotI. (B) Southern blot analysis of DNA from independent founder transgenic mice providing evidence for multiple copy numbers of 5 to 7 in three founders (lanes 2, 3, and 5) and a fourth with less than one copy in lane 4. Lane 1 contains DNA from a C57BL/6J control mouse. The transgene fragments migrate at 4.2 and $3.0 \mathrm{~kb}$, the latter is also present in the endogenous gene.

cells expressing UCP and the aP2 protein were identified by horse radish peroxidase double antibody coupled protocols. The anti-UCP antibody was prepared by us, and the anti-aP2 antibody was a gift of Dr. David Bernlohr.

Animals. Mice were maintained on a 12-h light-dark cycle and fed standard old Guilford mouse chow in which $24.9 \%$ of its calories are obtained from protein and $8.2 \%$ from fat.

\section{Results}

Construction and expression of the transgene. A transgenic line was produced with a DNA construct that was composed of 5.4 $\mathrm{kb}$ of the 5' flanking fat specific regulatory region of the aP2 gene and $21 \mathrm{bp}$ of its first exon ligated to the BglI site located in the first exon of the $U c p$ (20) (Fig. 1). This construct was expected to direct $U c p$ expression to both brown fat and white fat, in contrast to the endogenous $U c p$ gene which is expressed exclusively in brown fat. In addition, the aP2-Ucp transgene would not be induced by adrenergic agents but be constitutively expressed. To analyze the expression of the aP2-Ucp gene at the RNA level, a primer extension assay was developed which took advantage of the structural differences at the $5^{\prime}$ ends of the transgenic and the endogenous gene products. This assay showed only one product of the predicted size $(180 \mathrm{bp})$ in the brown fat of nontransgenic mice and no trace of expression in RNA isolated from gonadal white fat. Transgenic mice showed two extension products in brown fat, one derived from the endogeneous gene ( $180 \mathrm{bp}$ ) and the other from the transgene (132 bp). The resolution of the endogenous and transgene transcripts 


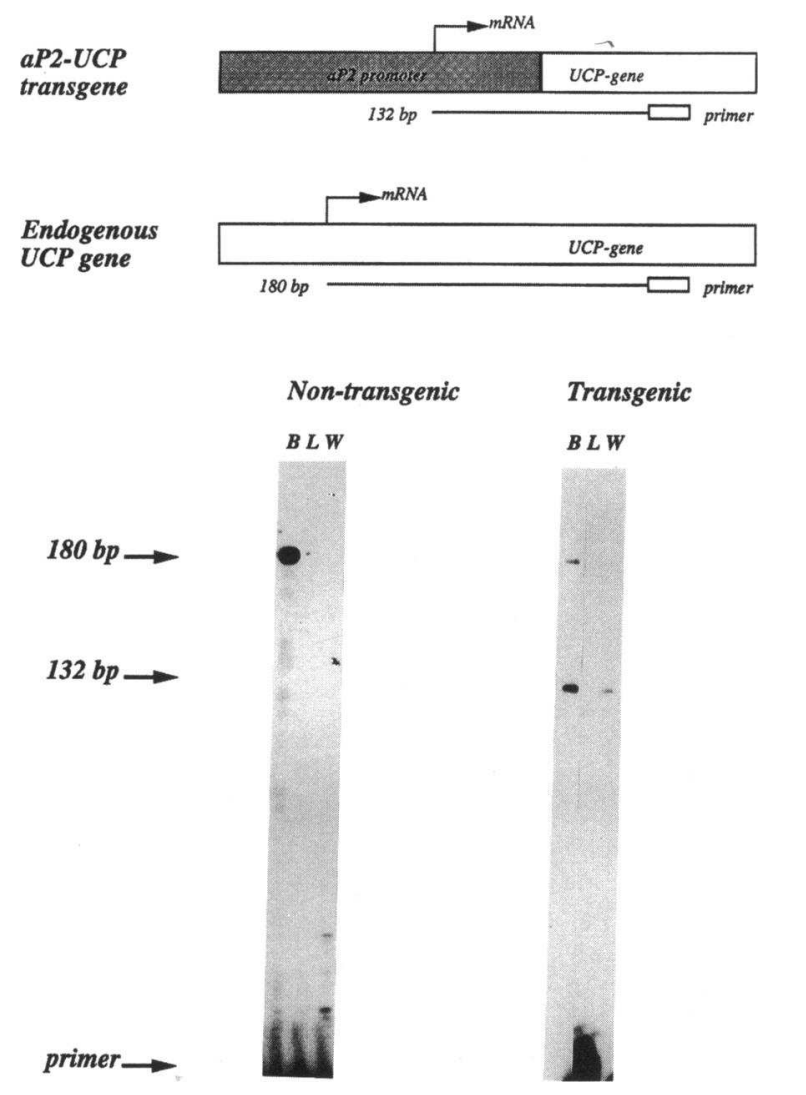

Figure 2. Determination of RNA levels by primer extension analysis. The transcription of the aP2-Ucp transgene initiates from the aP2 gene transcription start site within the aP2-Ucp promoter. The tissues analyzed were brown fat $(B)$, liver $(L)$ and white fat $(w)$. Details of the assay are given in Methods. A primer extended product is only detected in the brown fat of tissues from nontransgenic mice. In transgenic mice the brown fat has two products, the endogenous product of $180 \mathrm{bp}$ and the trangene product at $132 \mathrm{bp}$; no products are detected in the liver and a weak signal is detected in the white fat.

enabled us to determine the relative levels of endogenous and transgene expression. In the brown fat, the transgenic Ucp transcript was much more abundantly expressed than the endogenous gene transcript. Only the transgenic transcript was detected in white fat depots with similar levels of expression found in subcutaneous and peritoneal and in males and females (Fig. 2).

To evaluate the effects of changes in thermal requirements on mRNA production, RNA was isloated from the brown and white fat of mice maintained at $4^{\circ}, 20^{\circ}$, and $28^{\circ} \mathrm{C}$ (Fig. 3 ). In the brown fat of the transgenic mice, increases in ambient temperature resulted in the expected progressive decrease in the amount of transcript derived from the endogenous gene, while the transcript derived from the transgene was unaffected by the change in temperature. Similarly, the amount of mRNA produced in the white fat depots was unaffected by temperature.

The amount of UCP present in brown and white fat was determined by immunoblot analysis (Fig. 4). In order to detect all of the UCP present, subcellular fractions were prepared from homogenates by ultracentrifugation under conditions which sedimented all of the membranes. Semi-quantitative results were obtained by comparing signal intensities of UCP present in membrane preparations from fat tissue of transgenic and control mice to those observed from known amounts of purified preparations of UCP. Consistent with the RNA analysis, UCP was

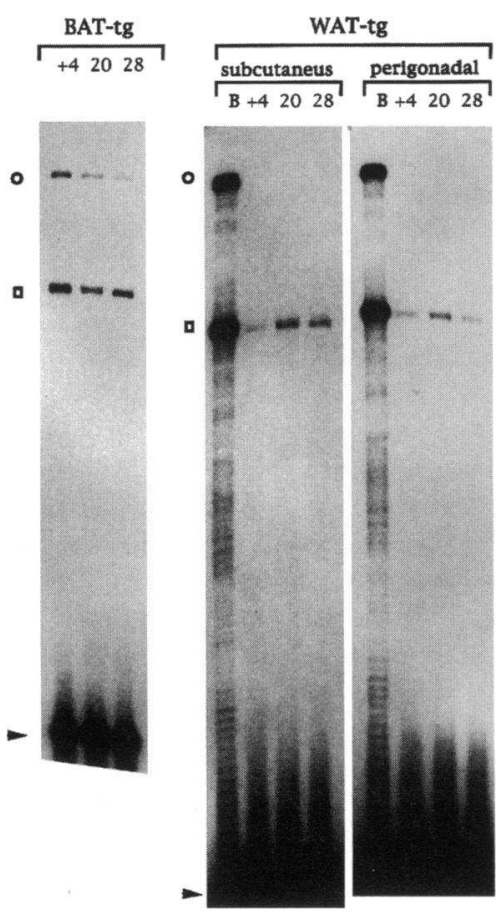

Figure 3. Effect of changes in ambient temperature on levels of $U c p$ mRNA derived from the endogenous gene and the aP2-Ucp transgene. Female mice were maintained at ambient temperature, $20,4^{\circ} \mathrm{C}$ for $12 \mathrm{~h}$ and $28^{\circ} \mathrm{C}$ for $3 \mathrm{~d}$. Total RNA from brown fat (BAT), subcutaneous fat from the femoral/ inguinal region and perigonadal fat were analyzed by the primer extension assay to determine relative $U c p$ mRNA levels.

detected in the white fat of transgenic mice and in the brown fat of both transgenic and control mice, but not in other tissues. Fractionation of the homogenates from the UCP containing tissues by differential centrifugation indicated that the UCP was associated with the mitochondrial fraction and that there was no UCP in the cytosol (data not shown). In brown fat, the level of UCP in the transgenic mice was virtually identical to that observed in control mice. Therefore, the additional capacity to synthesize UCP in brown fat due to the presence of the transgene did not in fact result in more UCP. The lower levels of $U c p$ transcript due to the reduced expression of endogenous $U c p$ gene did not result in lower levels of the protein, thus providing evidence that the regulation of UCP levels in brown fat adjusts to the synthesis of functionally active UCP from constitutively expressed aP2-Ucp. The concentration of UCP in the white fat of transgenic mice on the $\mathrm{C} 57 \mathrm{BL} / 6 \mathrm{~J}$ background is much lower than in brown fat $(0.5 \mu \mathrm{g} \mathrm{UCP} / \mathrm{mg}$ protein in white fat compared to $50 \mu \mathrm{g} \mathrm{UCP} / \mathrm{mg}$ protein in brown fat). Assuming that the total amount of white fat dissected from the various fat depots represents roughly one-half of the total white adipose tissue, the total content of UCP in white fat does not exceed $2 \%$ of the UCP of the interscapular brown fat (Table I).

Fat accumulation. Transgenic mice and their non-transgenic

\begin{tabular}{|c|c|c|c|c|c|c|c|c|c|c|}
\hline \multicolumn{4}{|c|}{ BAT } & \multicolumn{2}{|c|}{ EPI } & \multicolumn{2}{|c|}{ ING } & OVAR & \multicolumn{2}{|c|}{ Dorsal } \\
\hline c & tg & C & tg & C & tg & C & tg & C t & C & tg \\
\hline & $=$ & $=$ & - & & & & & & & - \\
\hline
\end{tabular}

Figure 4. Determination of UCP levels by immunoblot analysis. Subcellular mitochondrial membranous fractions were analyzed by immunoblot for their content of UCP as described in Methods. Equal amount of protein was applied to each lane of the gel. The brown fat $(B A T)$ epidydymal (EPI), inguinal (ING), ovarian (OVAR) and femoral (Dor$\mathrm{sal})$ fat depots from transgenic $(\mathrm{tg})$ and littermate control $(\mathrm{c})$ mice were analyzed. 


\begin{tabular}{|c|c|c|c|c|c|c|c|c|c|c|c|}
\hline & & \multicolumn{2}{|c|}{$\begin{array}{c}\text { Nontransgenic } \\
\text { BAT }\end{array}$} & \multicolumn{8}{|c|}{ Transgenic } \\
\hline & & \multirow[b]{2}{*}{ SA } & \multirow[b]{2}{*}{ TOTAL } & \multicolumn{2}{|c|}{ BAT } & \multicolumn{2}{|c|}{ Femoral } & \multicolumn{2}{|c|}{ Inguinal } & \multicolumn{2}{|c|}{ Gonadal } \\
\hline & & & & SA & TOTAL & SA & TOTAL & SA & TOTAL & SA & TOTAL \\
\hline \multirow[t]{3}{*}{ C57BL/6J } & Mean & 55.75 & 241.25 & 78.50 & 283.50 & $0.60-0.75$ & $0.36-0.52$ & $0.33-0.48$ & $0.06-0.09$ & $0.36-1.08$ & $0.71-2.86$ \\
\hline & SEM & 4.64 & 59.59 & 7.26 & 67.94 & & & & & & \\
\hline & (n) & 4 & 4 & 4 & 4 & 4 & 4 & 4 & 4 & 4 & 4 \\
\hline \multirow[t]{3}{*}{$\mathrm{C} 57 \mathrm{BL} / 6 \mathrm{~J}-A^{v y}$} & Mean & 38.17 & 131.00 & 43.50 & 136.50 & 1.47 & 1.80 & 1.82 & 2.00 & 1.42 & 13.78 \\
\hline & SEM & 3.68 & 14.43 & 3.35 & 13.41 & 0.57 & 0.62 & 0.54 & 0.54 & 0.21 & 2.67 \\
\hline & (n) & 6 & 6 & 6 & 6 & 6 & 6 & 6 & 6 & 6 & 6 \\
\hline
\end{tabular}

The content of UCP in tissues is given as specific activity (SA) in $\mu \mathrm{g} \mathrm{UCP}$ per mg of membranous protein and as the calculated amount of total $\mathrm{UCP}$ (given in $\mu \mathrm{g}$ ) in the tissue.

littermate controls, both on the C57BL/6J background, were monitored to detect changes in total body weight. During the first two months of age there were no consistent differences in total body weight nor in the weight of individual fat pads. Up to 6 mo of age differences in total body weight were still not reliably evident, but a reduction in the weight of the femoral fat depot became apparent, particularly in female mice at $\sim 3$ mo of age (Fig. 5). With increasing age the decline in the weight of the femoral fat continued, until at one year of age subcutaneous white fat depots were virtually undetectable. A generalized loss of subcutaneous fat was the first detectable effect of the transgene, as illustrated in the dorsal view of mice in Fig. 6. In contrast, the peritoneal fat, specifically the gonadal fat of the female, had increased in weight almost in proportion to the reduction in weight of subcutaneous fat (Fig. 6). These results are illustrated in Fig. 7 where the total body weight is correlated to the gonadal fat weight. It is apparent from this data that at any given body weight the ovarian fat pads are markedly larger in the transgenic mice. At six months of age, the effects of the aP2-Ucp transgene on fat deposition are not readily detectable except on the female femoral fat pad; how- ever, at one year of age striking differences are apparent in both sexes (Table II). In the transgenic mice significant reductions are found in total body weight and the weights of the femoral and mesenteric fat pads of both sexes and the renal fat pad was also reduced in male transgenic mice. In contrast, the gonadal fat continued to be heavier in in females and was not significantly changed in males. No differences in the weights of interscapular brown fat or the liver were detected at any age. Thus the transgene has differential effects on subcutaneous fat and gonadal fat depots that do not become apparent until the mouse reaches midlife. It is should also be pointed out that these nontransgenic, control C57BL/6J male mice, some weighing in excess on 50 grams, are obese.

Since no reductions in total body weight were initially detected in young mice carrying the transgene on the C57BL/6J background strain, the aP2-Ucp transgenic mice were crossed to C57BL $/ 6 \mathrm{~J}-A^{v y} /+$ genetically obese mice in order to determine whether the transgene could alter the development of obesity. The effects of the transgene on reducing body weight in young $A^{\text {vy }}$ mice ( 7 wk of age) were modest, but significant, causing a $15 \%$ reduction. However, with increasing age the differences

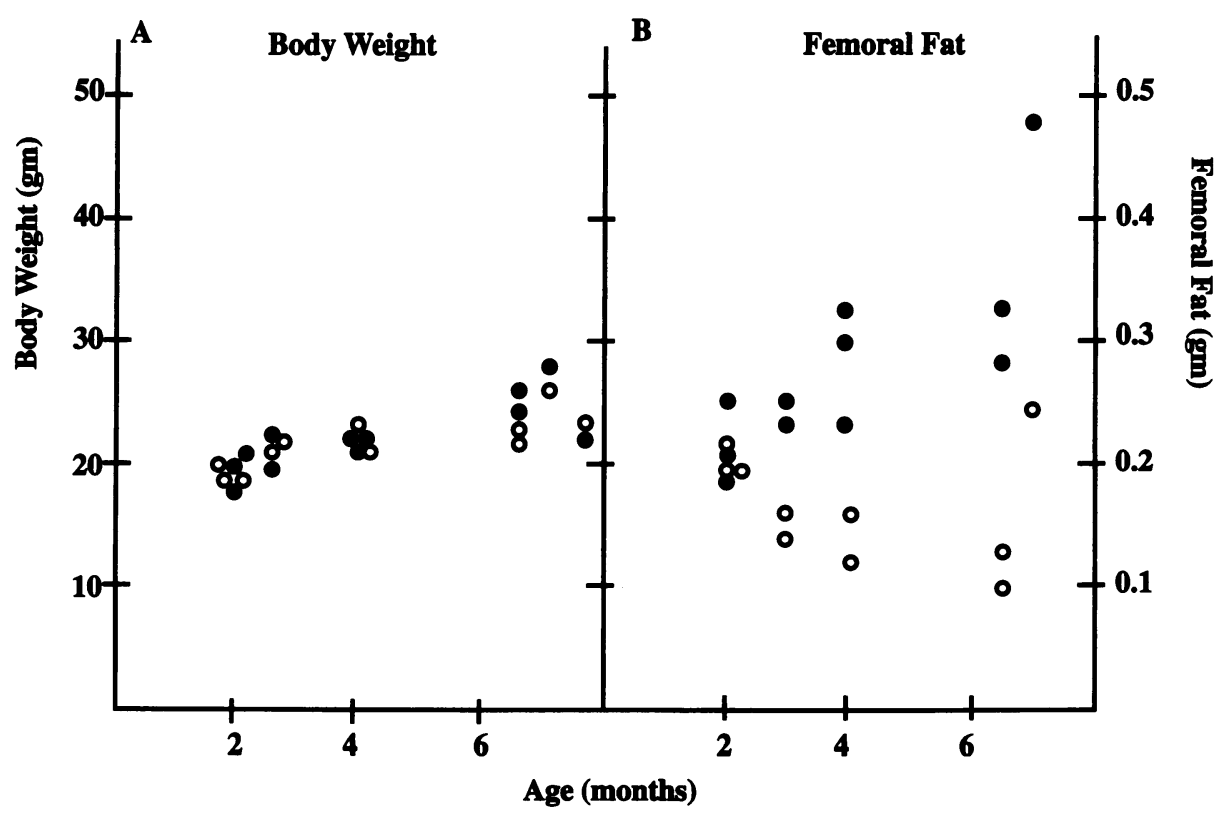

Figure 5. A comparison of changes in body weight $(A)$ and femoral/inguinal fat weight $(B)$ during aging in control $(\bullet)$ and transgenic $(O) C 57 \mathrm{BL} / 6 \mathrm{~J}$ mice. 


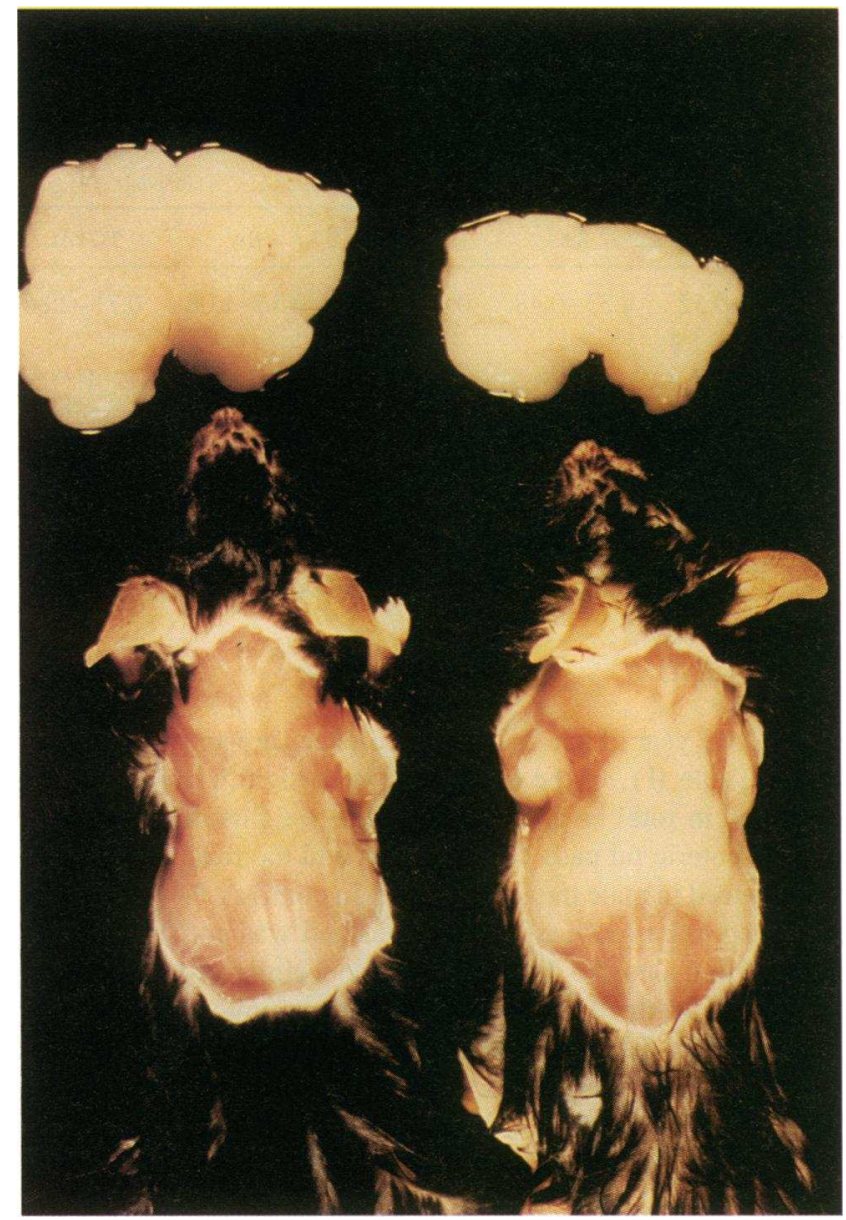

Figure 6. Dorsal view of aP2-Ucp transgenic (left) and littermate control C57BL/6J mice (right) at 9 mo of age illustrating the absence of subcutaneous white fat and the increase in periovarian white fat in the transgenic mouse compared with the nontransgenic mouse. The latter has a layer of white fat over the back but a smaller periovarian fat pad.

between transgenic and nontransgenic $A^{v y}$ increase; female transgenic mice weighed 34.6 grams or $\sim 13$ grams (73\%) less than the nontransgenic females at 6 to 7 mo of age (Table III). In a group of three 13-mo-old transgenic $A^{\text {vy }}$ mice, the females continued to maintain their weights at $\sim 35$ grams while nontransgenic $A^{v y}$ mice reached body weights of 55-60 grams corresponding to a $30-40 \%$ difference in body weight. Similar to the effects on standard C57BL/6J mice, $A^{\text {vy }}$ transgenic mice preferentially lost subcutaneous fat while the gonadal fat was only slightly reduced. Remarkably, the female transgenic $A^{v y}$ mice in this aged group appeared extremely healthy and weighed 35 grams, the same as the non- $A^{v y}$ nontransgenic littermates. Unfortunately, the nontransgenic $A^{v y}$ littermates had died by 13 mo of age. An important finding is that the expression from the endogenous $U c p$ gene in the old $A^{v y}$ transgenic mice has declined to $5 \%$ of the endogenous level observed in a 13mo-old nontransgenic mouse. The effect on males was less with the transgenic mice weighing $86 \%$ of the nontransgenic males.

When the level of UCP in brown fat of the $A^{v y}$ mice was determined (Table I), no significant difference was observed between the nontransgenic and aP2-Ucp transgenic mice, similar to expression on C57BL/6J mice. However, the concentrations and total UCP content in brown fat of $A^{v y}$ mice was 1.52.0-fold lower than that determined in non- $A^{\text {vy }} \mathrm{C} 57 \mathrm{BL} / 6 \mathrm{~J}$ mice.

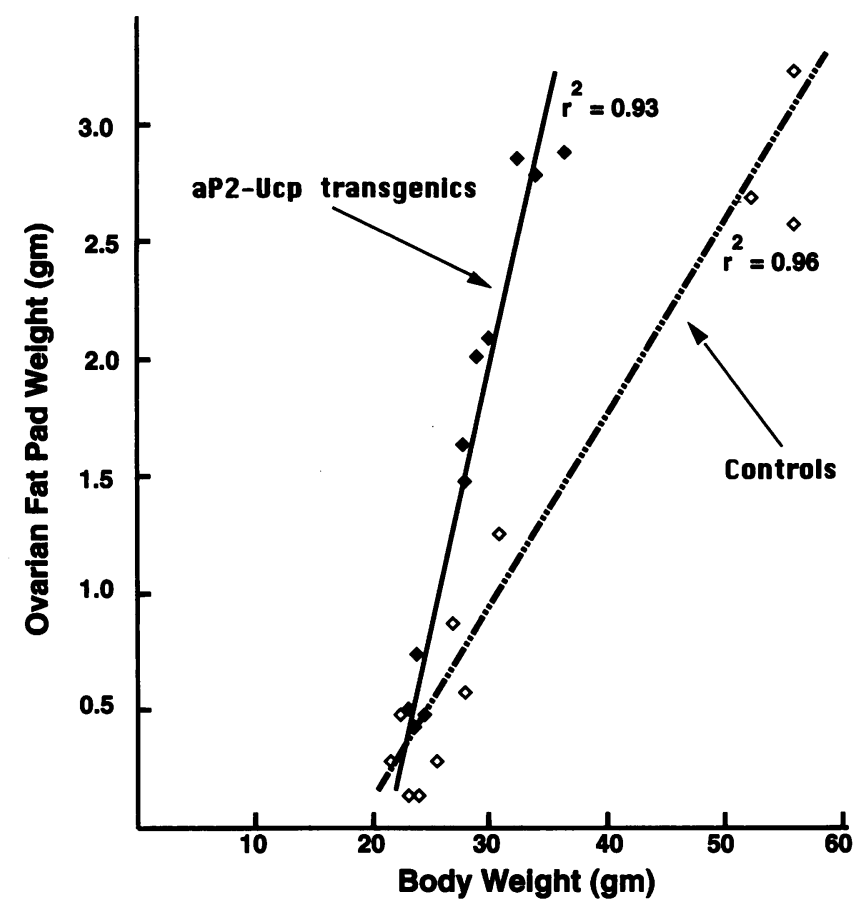

Figure 7. Graph which correlates the weight of the ovarian fat pad to total body weight with correlation coefficients of 0.93 and 0.96 in the aP2-Ucp transgenic and nontransgenic littermate control mice, respectively.

In contrast, the UCP content of the white fat depots (1.4-1.8 $\mu \mathrm{g} \mathrm{UCP} / \mathrm{mg}$ protein) in the $A^{v y}$ mice was significantly higher than in C57BL/6J mice. We estimate that the total UCP content of white fat in $A^{v y}$ transgenic mice is $\sim 10 \%$ of the amount

Table II. Body and Tissue Weights in Control and Transgenic Mice at 12-15 Months of Age

\begin{tabular}{lccc}
\hline & C57BL/6J & C57BL/6J.aP2-Ucp & Probability \\
\hline Females & & & \\
$(n)$ & 5 & 8 & \\
Body Weight & $35.74 \pm 0.88$ & $30.66 \pm 1.04$ & 0.0058 \\
Femoral Fat & $1.51 \pm 0.12$ & $0.23 \pm 0.03$ & 0.0002 \\
Gonadal Fat & $1.98 \pm 0.11$ & $2.52 \pm 0.21$ & 0.0752 \\
Renal Fat & $1.05 \pm 0.08$ & $1.09 \pm 0.13$ & 0.8441 \\
Mesenteric Fat & $0.76 \pm 0.06$ & $0.46 \pm 0.06$ & 0.0094 \\
Brown Fat & $0.18 \pm 0.01$ & $0.16 \pm 0.01$ & 0.4932 \\
Liver & $1.59 \pm 0.04$ & $1.63 \pm 0.13$ & 0.8196 \\
Males & & & \\
(n) & 11 & 8 & \\
Body Weight & $44.75 \pm 2.46$ & $38.35 \pm 0.94$ & 0.0483 \\
Femoral Fat & $1.61 \pm 0.24$ & $0.52 \pm 0.08$ & 0.0017 \\
Gonadal Fat & $2.24 \pm 0.24$ & $1.87 \pm 0.12$ & 0.2435 \\
Renal Fat & $0.96 \pm 0.13$ & $0.44 \pm 0.06$ & 0.007 \\
Mesenteric Fat & $1.05 \pm 0.15$ & $0.30 \pm 0.03$ & 0.0005 \\
Brown Fat & $0.27 \pm 0.04$ & $0.18 \pm 0.02$ & 0.0884 \\
Liver & $2.40 \pm 0.25$ & $2.06 \pm 0.13$ & 0.2884 \\
& & & \\
\hline
\end{tabular}

All data is reported as gm of tissue \pm standard error of the mean. The number of animals in each group is given by $(n)$. Probability ( 2 tail) estimates were calculated by a $t$ test with Statview software. 
Table III. Effect of the aP2-Ucp Gene on Body Weights

\begin{tabular}{|c|c|c|c|c|c|c|c|c|}
\hline \multirow[b]{2}{*}{$A^{n y}$ genotype } & \multicolumn{4}{|c|}{ Female } & \multicolumn{4}{|c|}{ Male } \\
\hline & $+1+$ & $+1+$ & $A^{v y} /+$ & $A^{v y /} /+$ & $+/+$ & $+/+$ & $A^{v y} /+$ & $A^{v y} /+$ \\
\hline aP2-Ucp Transgene & No & Yes & No & Yes & No & Yes & No & Yes \\
\hline$(n)$ & 4 & 6 & 8 & 9 & 7 & 8 & 7 & 4 \\
\hline \multicolumn{9}{|l|}{ Body weights (grams) } \\
\hline Mean & 22.71 & 23.26 & $47.45^{*}$ & $34.63 *$ & 29.82 & 28.37 & $51.14^{\ddagger}$ & $43.95^{\ddagger}$ \\
\hline Standard error & 0.72 & 0.33 & 3.36 & 1.63 & 0.93 & 0.70 & 2.88 & 1.49 \\
\hline
\end{tabular}

The aP2-Ucp gene caused significant differences in the body weight $(P<0.01)$ of $\mathrm{A}^{\text {vy }} /+$ females $(*)$ and males $\left({ }^{\ddagger}\right)$ but not in the $+/+$ mice of either sex.

present in interscapular brown fat. Accordingly, the amount of UCP in the white fat of transgenic mice is several fold higher in the presence of genetically determined obesity.

Cell numbers and fat morphology. To determine whether fat cell size or number accounted for the increase in gonadal fat pad weight, fat tissue was dissociated with collagenase and the adipocytes were separated from the stromal vascular fraction by centrifugation. Cells were floated on embryological depression slides and photographed in the presence of an ocular micrometer (21). Enlarged prints of the fields were produced and the sizes of cells were determined. This method established that the adipocytes isolated from the aP2-Ucp transgenic mice were much smaller than those from nontransgenic mice; however most striking were the bizarre shapes of adipocytes isolated from the aP2-Ucp transgenic mice (data not shown). These cells were also fragile as evidenced by the frequency with which they ruptured as they were viewed under the microscope. The attempt to determine cell numbers by cell isolation techniques was not successful; however, it provided preliminary evidence that the adipocytes from the transgenic mice were different than those from the nontransgenic mice and semiquantitative evidence that more cells were present in the gonadal fat of aP2Ucp transgenic mice.

Histological analysis of paraffin-embedded fat tissue stained with hematoxylin and eosin provided direct evidence of the change in tissue morphology. Photomicrographs of sections from the ovarian and femoral fat pads of $A^{v y}$ transgenic and nontransgenic mice are shown in Fig. 8. Both fat pads in the nontransgenic mice (Fig. 8, $A$ and $B$ ) show a uniform field of adipocytes with a large monocular lipid droplet surrounded by a thin ring of cytpolasm. In contrast, the ovarian fat pads from the transgenic mouse (Fig. $8 \mathrm{C}$ ) show a heterogeneous field composed of cells with the typical adipocyte morphology, but variable in size, interspersed with large numbers of a small lipid-depleted cell. These small cells appear as the animals begin to age and their numbers increase during this period (Fig. 9). They are also more abundant in transgenic mice which are susceptible to obesity. For example, only small numbers are detected in transgenic mice on the normal C57BL/6J background (Fig. $10 \mathrm{~B}$ ) as compared with the large numbers in the gonadal pad from obese $A^{v y}$ aP2-Ucp transgneic mice (Fig. 8, 9 , and $10 C$ ). Only a few small cells could be detected in the femoral fat pads, but this tissue, which is greatly reduced in the transgenic mice, was principally characterized by the large blood vessels coursing throughout the tissue (Fig. 8). The reduction in the weight of the femoral fat pad is the earliest known phenotypic difference to result from the presence of the aP2Ucp transgene.
In some animals the number of these cells exceeded the number of large, fully differentiated white adipocytes. To provide an estimate of the increase in cell number represented by the adipocyte derivatives, the DNA content of the gonadal fat pad was determined. No significant changes in DNA content were found in transgenic vs nontransgenic mice on the C57BL/ $6 \mathrm{~J}$ background ( $\sim 0.9 \mu \mathrm{g} \mathrm{DNA} / \mathrm{gm}$ of tissue); however, $A^{v y}$ mice carrying the transgene had a highly significant 5-10-fold increase in DNA content (4.6-8.4 $\mu \mathrm{g}$ DNA/gm of tissue). Based upon the histology of the tissues which show few of the small cells in fat pads of transgenic mice on the normal C57BL/ $6 \mathrm{~J}$ background and a lack of a differences in DNA content, it is probable the 5-10-fold increase in DNA content of the fat pads from transgenic $A^{v y}$ mice is due to the expansion of the small cell population in the tissue.

The appearance within fat of the small cells described above is not a common occurrence; in fact we were unable to find any references documenting a similar finding. To characterize this cell type, tissue sections were analyzed by immunohistochemistry using antibodies specific for UCP, the aP2 protein and ly 5.2, an antigen specific for hemopoietically-derived cells from C57BL/6J mice (22). The small cells reacted positively with both anti-UCP and anti-aP2 antibodies suggesting that they are adipocyte derivatives, even though they do not accumulate lipids. We shall refer to these cells as adipocyte derivatives. The absence of a reaction with anti-ly 5.2 (data not shown) underscores the fact that these cells are distinct from the small number of lymphocytes that are occasionally present in the ovarian fat pads of the transgenic mice, particularly around the blood vesicles.

On the basis of histological exmination, there appeared to be more adipocyte derivatives in female than in male gonadal fat. The subcutaneous femoral fat depots also contain adipoblasts but in small numbers; however, the most striking feature of this tissue was the presence of large areas composed of a fibroblastic-like cell devoid of lipid stores.

\section{Discussion}

Our experiments demonstrate that the enhanced expression of Ucp can reduce obesity. To accomplish this we made a transgenic mouse in which the $U c p$ gene is under the control of the aP2 gene promoter. This mouse has a low level of $U c p$ expression in white fat depots and constitutive as well as regulatable expression from the endogenous $U c p$ gene in brown fat. As determined by immunoblots the amount of UCP present in white fat was estimated to be at most $10 \%$ of the level normally detected in brown fat. Despite the presence of a constitutively 

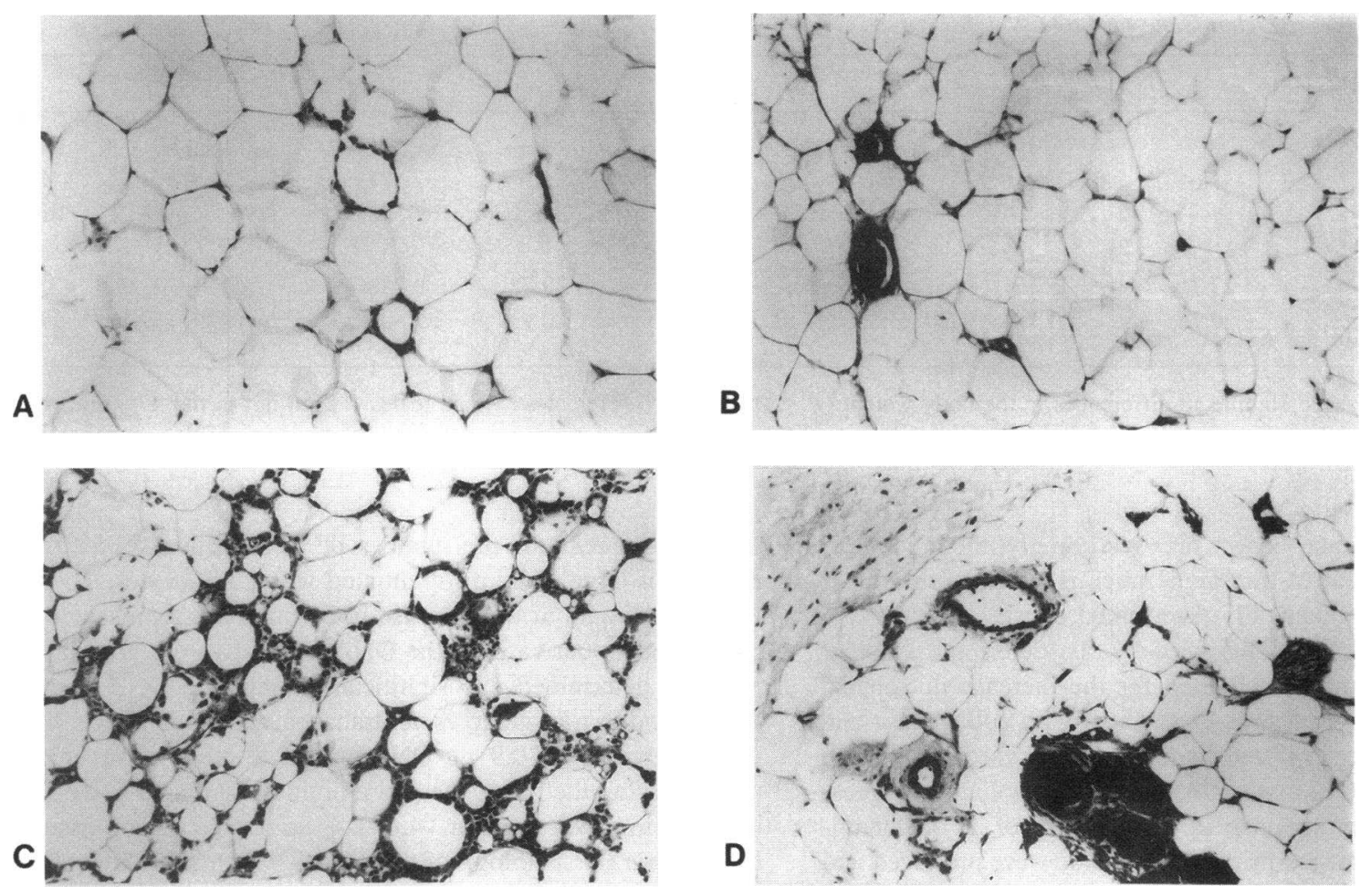

Figure 8. Photomicrographs of paraffin-embedded hematoxylin and eosin stained sections from the ovarian $(A$ and $C)$ and femoral $(B$ and $D)$ fat depots. Tissues were from 10-mon-old nontransgenic $A^{v y}$ mice $(A$ and $B)$ and transgenic $A^{v y}$ mice $(C$ and $D)$.

expressed transgene and a normal endogenous gene, there is no increase in the level of UCP in the brown fat of the transgenic mice. The determination of RNA levels by primer extension analysis suggests that the levels of the protein are normalized by down regulation of the endogenous gene.

We have found phenotypic changes associated only with adipose tissue; the animals appear healthy in all respects, they are reproductively active and live a normal life span. The pheno- typic characteristics associated with the adipose tissue were more complex than simply a reduction in white fat stores. Interactions of age, propensity for obesity and sex of the transgenic mice are involved in defining the phenotype. Sexual dimorphism has been observed in other models of genetic obesity in mice (23) and it is therefore not surprising to find it also in this transgenic model. The molecular basis of sexual dimorphism in obesity is not understood. Most interesting is the role that obe-

A

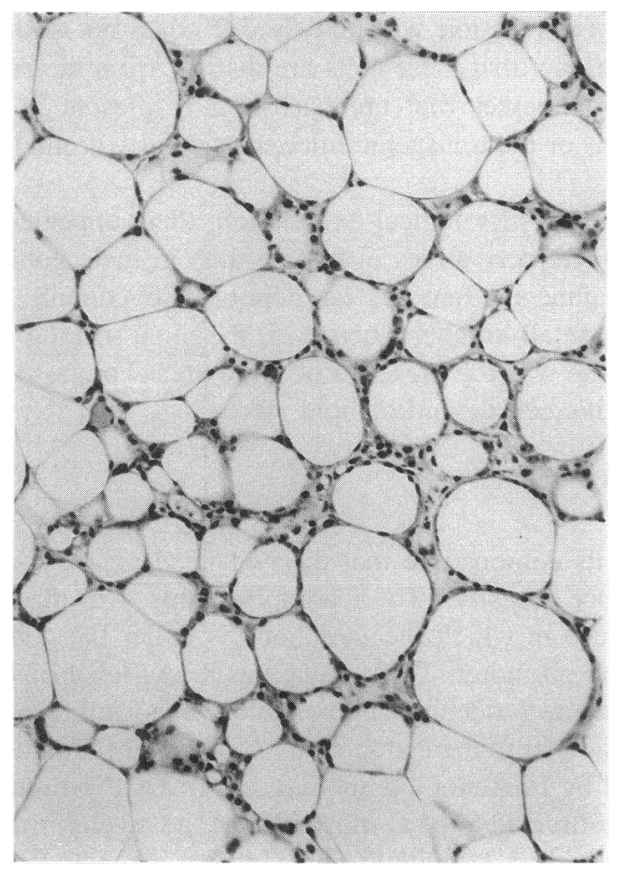

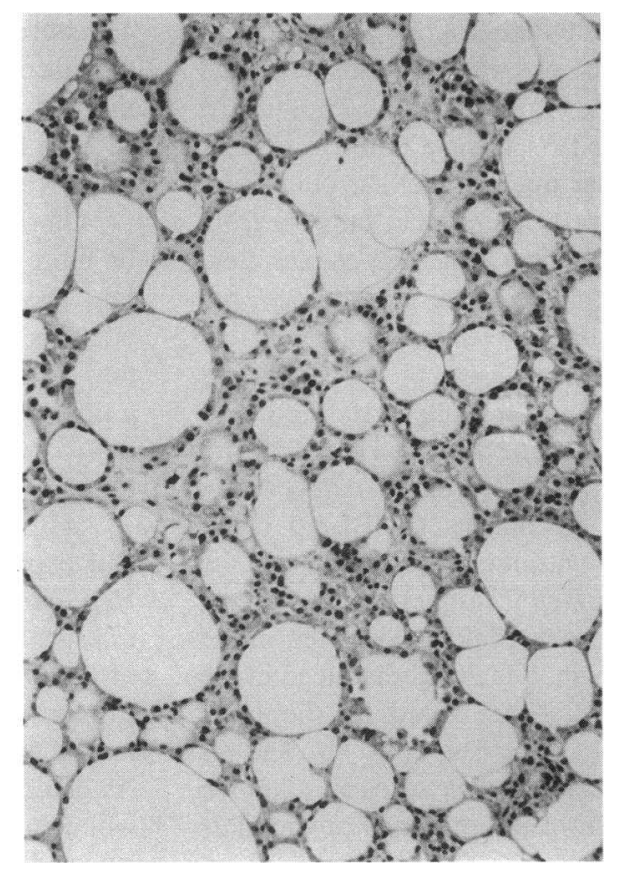

Figure 9. Illustration of the increase in the number of a novel adipocyte derivative in the fat pads of aP2-Ucp transgenic mice carrying the the $A^{v y}$ gene at 6.5 mo $(A)$ and 13 months $(B)$ of age. Paraffin-embedded sections were stained with hematoxylin and eosin. 

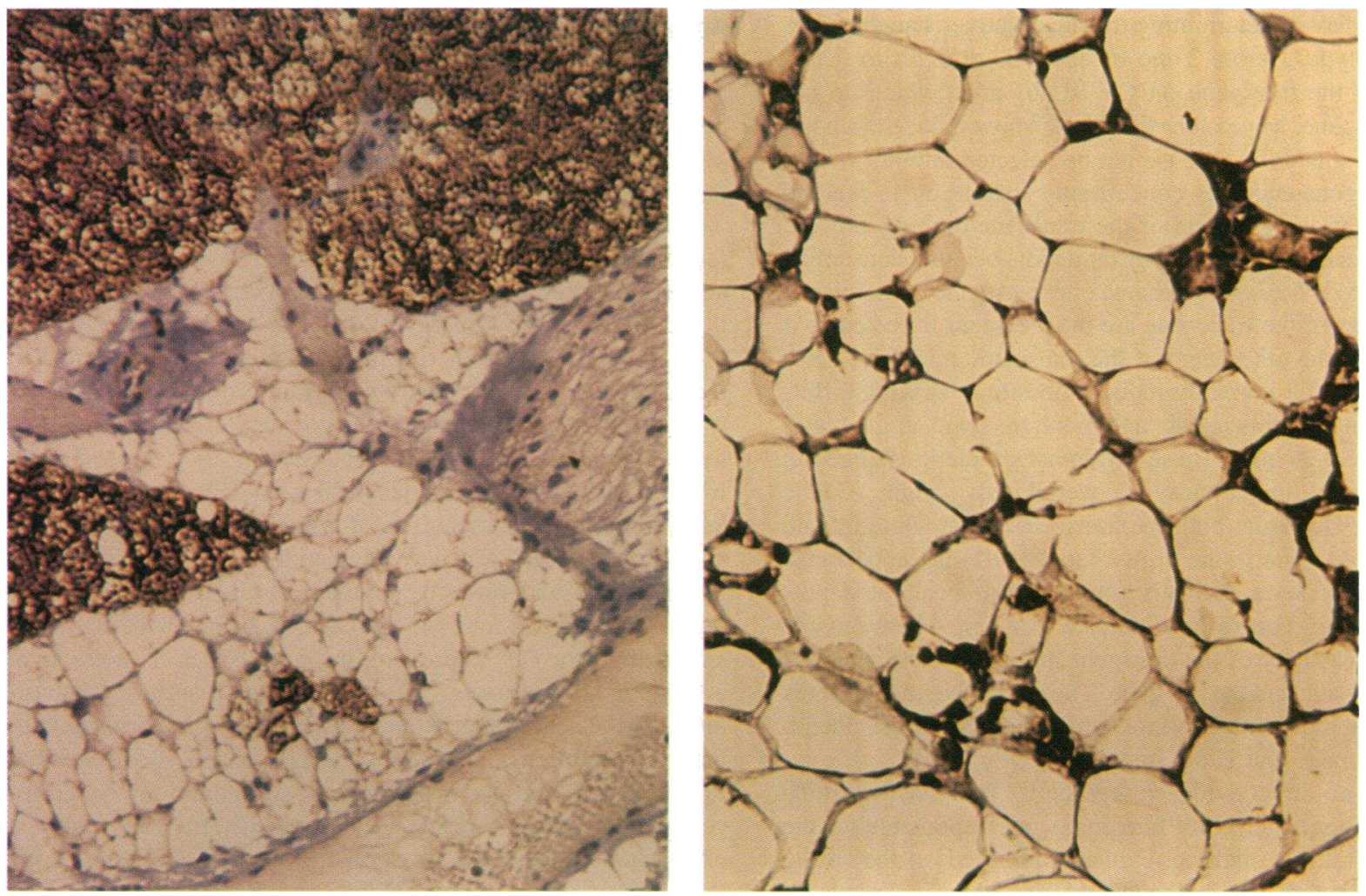

$\mathbf{A}$

B
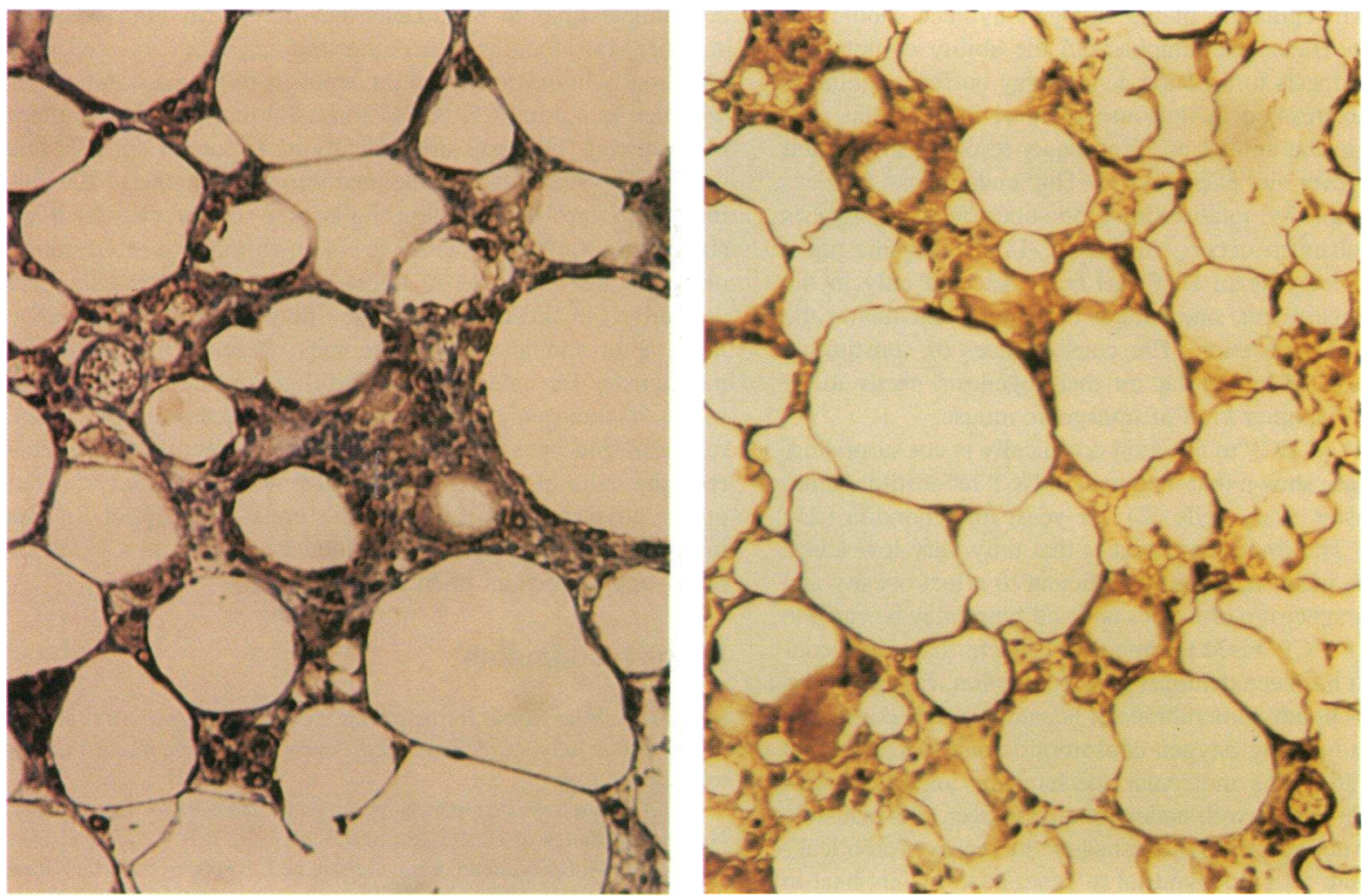

C

D

Figure 10. Immunohistology of $(A)$ brown fat from a C57BL/6J female; $(B)$ ovarian fat from an aP2-Ucp transgenic C57BL/6J female mouse at 10 mo of age; $(C$ and $D)$ ovarian fat from an aP2-Ucp . $A^{\text {vy }}$ C57BL/6J female mouse 10 mo of age. Anti-UCP antisera were used in samples $(A$, $B$, and $C$ ) and anti-aP2 protein antisera were used in sample $(D)$. The staining patterns illustrate that the adipocyte derivatives are positive for both $\mathrm{UCP}$ and aP2 protein. 
sity and age play in determining the quantitative characteristics of the phenotype. Before $3 \mathrm{mo}$ of age it is difficult to detect any effect of the transgene on C57BL/6J mice which do not carry the $A^{\text {vy }}$ gene. Mice older than 3 mo show reduced femoral fat; however, this difference cannot be detected in body weight because the gonadal fat is concurrently increasing in weight. By one year of age an effect of the transgene on reductions in overall body weight and on other fat depots become detectable. At this age C57BL/6J mice become obese with the consequence that the effects of the transgene are most evident in the context of obesity. On the other hand, if the transgenic mice also carry the $A^{v y}$ gene which normally induces obesity, a striking difference between the transgenic and nontransgenic animal was found at an earlier age. These differences include changes in (1) the weight of the fat pads; (2) overall body weight; (3) the expression of Ucp from both the transgene in the white fat and the endogenous gene in the brown fat; and (4) the appearance of a novel adipocyte derivative in the peritoneal fat depots of the $A^{v y}$ mice. The results indicate a synergy between the thermogenic capacity of the transgene and the obesity which is augmented by age and the $A^{\text {vy }}$ gene. The sex of the mice appears to be another independent factor which influences the phenotypes in a manner that is not understood.

We have no direct evidence that the UCP derived from the transgene is thermogenically functional and responsible for the reduction in fat. The indirect evidence is based on the strong down regulation of the endogeneous $U c p$ gene in brown fat in the presence of this transgene provides evidence that the constitutively active aP2-Ucp transgene must be functional otherwise a down regulation of the endogenous gene should not occur. Himms-Hagen has emphasized the ability of nonshivering thermogenesis to function as a energy buffer modulating its level of expression in response to level of heat that may be produced in the animal as a consequence of environmental temperature, fever and exercise (7). That endogenous $U c p$ expression is reduced in relationship to the obesity stress suggests a similar mechanism occurrs in the aP2-Ucp transgenic mice. Although the increase in UCP has been detected only in the white fat compartment, one cannot be certain that this is the basis for the fat reduction. The consequences of constitutive Ucp expression in brown fat on thermogenesis needs to be evaluated with another kind of transgenic mouse.

The ability of UCP to function ectopically is not surprising, since it has been shown that mammalian UCP reconstituted into Chinese hamster ovary cells (24) or yeast mitochondria (25) is functional. The important point is that only very low levels of UCP in the white fat may be sufficient to affect obesity and that a broader spectrum of tissues and cell types may be capable of harboring a UCP based thermogenic system that could control obesity. It has been demonstrated that proton leakage across the inner mitochondrial membrane of hepatocytes can contribute significantly to resting oxygen consumption and therefore heat production (26). The molecular mechanisms underlying this proton leakage are not well understood. However, it is plausible that the UCP derived from the transgene increases proton leakage in the white fat mitochondrial to generate sufficient heat to reduce fat stores in the animals of this study. It also follows that mechanisms to increase mitochondrial proton leakage, even independent of UCP, could be effective in altering energy balance.

The earliest and largest difference in fat accumulation occurred in the reduction of the femoral/inguinal fat pad. With the exception of interscapular brown fat, which did not change in size in the transgenic mice, the subcutaneous fat depots were all reduced; but unlike the femoral-inguinal fat, the other depots of subcutaneous fat are difficult to dissect cleanly and reproducibly from the mouse. Importantly, the level of expression of the aP2-Ucp transgene in the femoral fat was less not higher than that measured in gonadal fat where there was a increase in the weight of the tissue. This suggests that the changes in regional fat metabolism in this animal is not determined by a mechanism autonomous for each fat pad, rather alterations and adjustments in the equilibrium of energy metabolism occur at the systemic level. Why the subcutaneous fat is privileged to be the first to reduce fat stores is an important and unresolved question.

The appearance of a cell in the gonadal fat which is positive for UCP and the aP2 protein suggests that the cell is derived from an adipocyte though it lacks the monolocular or multilocular lipid vesicles characteristic of white fat or brown fat. Since all of the $U c p$ mRNA is derived from the aP2-Ucp in the white fat transgene and there is no trace of the endogenous $U c p$ mRNA (see Fig. 2 and 3), the cells in the gonadal fat which are positive for $U c p$ expression have not arisen de novo from a brown adipocyte stem cell in the stromal vascular compartment. The absence of an accumulation of mitochondria (unpublished observations, X.X. Koza and L.P. Kozak) indicates that expression of $U c p$ is not sufficient to stimulate mitochondriogenesis, a conclusion reached independently from our analysis of brown adipocyte cell lines (27). Since the aP2 gene is one of the late stage markers of adipocyte differentiation program (28), it is possible that the adipocyte derivatives originate from white preadipocytes. However, it is unclear why they do not accumulate lipid to the extent that they form lipid vesicles. Another consideration concerning the origins of this cell type particularly in the peritoneal fat depots is its increase in number with age in normal C57BL/6J mice. Furthermore, the number of these cells increases dramatically in $A^{\text {vy }}$ obese mice. Is this cell an adipocyte that is generated during the aging of the animal, and is proliferating at a higher rate in animals which are susceptible to obesity? Since it is known that the proliferation of adipocytes increases in obese animals (29) the adipocyte derivatives in the transgenic mice may be those which arise in an adult animal when it becomes obese. Accordingly, the mechanisms for enhanced cell proliferation are still occurring in the $A^{v y}$ transgenic mice but the lack of excess fat for storage results in truncated differentiation. If these speculations are correct, the cells in the fat pad would reflect the obesity related proliferative capacity of the animal's preadipocyte pool. Studies in progress with a high fat diet induced obesity in C57/BL6J mice support such an interpretation.

\section{Acknowledgments}

We thank Ulrike Kozak for help with the RNA analyses. The Jackson Laboratory is fully accredited by the American Association of Laboratory Animal Care.

This research was supported by an award from Pfizer Inc. to LPK, National Institutes of Health grants HD-29149 to L.P. Kozak and DK31405 to B.M. Spiegelman, a travel grant to J. Kopecky from the Grant Agency of the Czech Republic and a Jackson Laboratory Fellowship to S. Enerbäck.

\section{References}

1. Coleman, J. E. 1980. Metabolic interrelationships between carbohydrates, lipids and proteins. In Metabolic Control and Disease. P. K. Bondy, and L. E. Rosenberg, editors. W. B. Saunders, Philadelphia. 161-274. 
2. Nicholls, D. G., and R. M. Locke. 1984. Thermogenic mechanisms in brown fat. Physiol. Rev. 64:1-64.

3. Cannon, B., and J. Nedergaard. 1985. The biochemistry of an inefficient tissue: brown adipose tissue. Essays Biochem. 20:110-164.

4. Houstek, J., J. Kopecky, and Z. Drahota. 1978. Specific properties of brown adipose tissue mitochondrial membrane. Comp. Physiol. 60B:209-214.

5. Rothwell, N. J., and M. J. Stock. 1979. A role for brown adipose tissue in diet-induced thermogenesis. Nature (Lond.). 281:31-35.

6. Himms-Hagen, J. 1984. Brown adipose tissue thermogenesis, energy balance and obesity. Can. J. Biochem. Cell. Biol. 62:610-617.

7. Himms-Hagen, J. 1989. Brown adipose tissue and obesity. Prog. Lipid Res. 28:67-115.

8. Himms-Hagen, J. 1992. Brown adipose tissue metabolism. In Obesity. P. Bjorntorp, and B. N. Brodoff, editors. J. B. Lippincott Company, Philadelphia. $15-34$.

9. Lowell, B. B., V. S-Susulic, A. Hamann, J. A. Lawitts, J. Himms-Hagen, B. B. Boyer, L. P. Kozak, and J. S. Flier. 1993. Development of obesity in transgenic mice after genetic ablation of brown adipose tissue. Nature (Lond.). 366:740-742.

10. Ross, S. R., R. A. Graves, A. Greenstein, K. A. Platt, H. L. Shyn, B. Mellovitz, and B. M. Spiegelman. 1990. A fat-specific enhancer is the primary determinant of gene expression for adipocyte P2 in vivo. Proc. Natl. Acad. Sci. USA. 87:9590-9594.

11. Boyer, B. B., and L. P. Kozak. 1991. The mitochondrial uncoupling protein gene in brown fat: correlation between DNAse hypersensitivity and expression in transgenic mice. Mol. Cell. Biol. 11:4147-4156.

12. Wagner, T. E., P. C. Hoppe, J. D. Jollick, D. R. Scholl, R. H. Hodinka, and J. B. Gault. 1981. Microinjection of a rabbit $\beta$-globin gene into zygotes and its subsequent expression in adult mice and their offspring. Proc. Natl. Acad. Sci. USA. 78:6376-6380.

13. Feinberg, A. P., and B. Vogelstein. 1983. A technique for radiolabelling DNA restriction endonuclease fragments to high specific activity. Anal. Biochem. 132:6-13.

14. Chomczynski, P., and N. Sacchi. 1987. Single-step method of RNA isolation by acid guanidium thiocyanate-phenol-chloroform extraction. Anal. Biocem. 162:156-159.

15. Derman, E., K. Krauter, L. Walling, C. Weinberger, M. Ray, and J. E. Darnell, Jr. 1981. Transcriptional control in the production of liver-specific mRNAs. Cell. 23(3):731-739.

16. Houstek, J., J. Kopecky, R. Zdenek, and T. Soukup. 1988. Uncoupling protein in embryonic brown adipose tissue-existence of nonthermogenic and thermogenic mitochondria. Biochim. Biophys. Acta. 935:19-25.
17. Smith, P. K., R. I. Krohn, G. T. Hermanson, A. K. Mallia, F. H. Gartner, M. D. Provenzano, E. K. Fujimoto, N. M. Goekke, B. J. Olson, and B. C. Klenk. 1985. Measurement of protein using bicinchoninic acid. Anal. Biochem. 150:7685.

18. Klingenberg, M. 1988. Nucleotide binding to uncoupling protein. Mechanism ofcontrol of by protonation. Biochemistry. 27:781-791.

19. Schaffner, W., and C. Weissman. 1973. A rapid, sensitive and specific method for the determination of protein in dilute solution. Anal. Biochem. 56:502 514.

20. Kozak, L. P., J. H. Britton, U. C. Kozak, and J. M. Wells. 1988. The mitochondrial uncoupling protein gene. Correlation of exon structure to transmembrane domains. J. Biol. Chem. 263(25):12274-12277.

1. Di Girolamo, M. S. Mendlinger, and J. W. Fertig. 1971. A simple method to determine fat cell size and number in four mammalian species. Am. J. Physiol. $221(3): 850-858$

22. Shen, F. W. 1981. Monoclonal antibodies to mouse lymphoid differentiation antigens. In Monoclonal Antibodies and T cell Hybridomas: perspectives and Technical Advances. G. J. Hammerling, U. Hammerling, and J. F. Kearney, editors. Elsevier/North Holland, New York. 25.

23. Surwit, R. S., C. M. Kuhn, C. Cochrane, J. A. McCubbin, and M. N. Feinglos. 1988. Diet-induced type II diabetes in C57BL/6J mice. Diabetes. 37:1163-1167.

24. Casteilla, L., O. Blondel, S. Klaus, S. Raimbault, P. Diolez, F. Moreau, F. Bouillaud, and D. Ricquier. 1990. Stable expression of functional mitochondrial uncoupling protein in Chinese hamster ovary cells. Proc. Natl. Acad. Sci. USA. 87:5124-5128.

25. Murdza-Inglis, D. L., H. V. Patel, K. B. Freeman, P. Jezek, D. E. Orosz, and K. D. Garlid. 1991. Functional reconstitution of rat uncoupling protein following its high level expression in yeast. J. Biol. Chem. 260(18):11871-11875.

26. Porter, R. K., and M. D. Brand. 1993. Body mass dependence of $\mathrm{H}+$ leak in mitochondria and its relevance to metabolic rate. Nature (Lond.). 362:628630.

77. Kozak, U. C., and L. P. Kozak. 1994. Norepinephrine-dependent selection of brown adipocyte cell lines. Endocrinology. 134(2):906-913.

28. Ailhaud, G. A., B. Bertrand, S. Barcellini-Couget, S. Bardon, R. M. Catalioto, C. Dani, S. Deslex, P. Diran, A. Doglio, A. Fignéres-Pradiues, C. Forest, D. Gaillard, P. Grimaldi, R. Negrel, and C. Vannier. 1990. Cellular and molecular aspects of adipose tissue growth. In Obesity: Towards a Molecular Approach. G. A. Bray, D. Ricquier, and B. M. Spiegelman, editors. Wiley-Liss, New York. 219-236.

29. Salans, L. B., S. W. Cushman, and R. E. Weissman. 1973. Studies of human adipose tissue: adipose cell size and number in obese and nonobese patients. J. Clin. Invest. 52:929-941. 